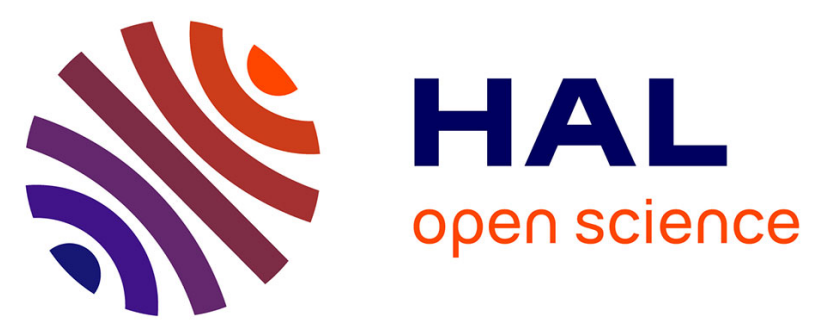

\title{
IMPACT OF UK NATIONAL GUIDELINES BASED ON FRAX® - COMPARISON WITH CURRENT CLINICAL PRACTICE
}

Nicola Crabtree, Natalie Bebbington, Deirdre Chapman, Yasmin Wahid, John Ayuk, Chris Boivin, Mark S Cooper, Neil Gittoes

\section{To cite this version:}

Nicola Crabtree, Natalie Bebbington, Deirdre Chapman, Yasmin Wahid, John Ayuk, et al.. IMPACT OF UK NATIONAL GUIDELINES BASED ON FRAX® - COMPARISON WITH CURRENT CLINICAL PRACTICE. Clinical Endocrinology, 2010, 10.1111/j.1365-2265.2010.03844.x . hal-00553274

\section{HAL Id: hal-00553274 https://hal.science/hal-00553274}

Submitted on 7 Jan 2011

HAL is a multi-disciplinary open access archive for the deposit and dissemination of scientific research documents, whether they are published or not. The documents may come from teaching and research institutions in France or abroad, or from public or private research centers.
L'archive ouverte pluridisciplinaire HAL, est destinée au dépôt et à la diffusion de documents scientifiques de niveau recherche, publiés ou non, émanant des établissements d'enseignement et de recherche français ou étrangers, des laboratoires publics ou privés. 


\section{CLINICAL ENDOCRINOLOGY}

\section{IMPACT OF UK NATIONAL GUIDELINES BASED ON FRAX® - COMPARISON WITH CURRENT CLINICAL PRACTICE}

\begin{tabular}{|r|l|}
\hline Journal: & Clinical Endocrinology \\
\hline Manuscript ID: & CEN-2010-000080.R1 \\
\hline Danuscript Type/Office: & 1 Original Article - UK/Europe \\
\hline Author: & 07-May-2010 \\
\hline Complete List of Authors: & $\begin{array}{l}\text { Crabtree, Nicola; Queen Elizabeth Hospital, Bone Densitometry } \\
\text { Bebbington, Natalie; Queen Elizabeth Hospital, Bone Densitometry } \\
\text { Chapman, Deirdre; Queen Elizabeth Hospital, Bone Densitometry } \\
\text { Wahid, Yasmin; Queen Elizabeth Hospital, Bone Densitometry } \\
\text { Ayuk, John; Queen Elizabeth Hospital, Endocrinology } \\
\text { Boivin, Chris; Queen Elizabeth Hospital, Bone Densitometry } \\
\text { Cooper, Mark; University of Birmingham, Institute of Biomedical } \\
\text { Research } \\
\text { Gittoes, Neil; Queen Elizabeth Hospital, Endocrinology }\end{array}$ \\
\hline Key Words: & osteoporosis, fracture, FRAX, NOGG \\
\hline
\end{tabular}




\section{IMPACT OF UK NATIONAL GUIDELINES BASED ON FRAX ${ }^{\circledR}$ - COMPARISON WITH CURRENT CLINICAL PRACTICE}

Short title: Impact of FRAX ${ }^{\circledR}$

Crabtree $\mathrm{NJ}^{1}$, Bebbington $\mathrm{NA}^{1}$, Chapman $\mathrm{DM}^{1}$, Wahid $\mathrm{YS}^{1}$, Ayuk $\mathrm{J}^{2}$, Boivin $\mathrm{CM}^{1}$, Cooper $\mathrm{MS}^{2}$, Gittoes NJL ${ }^{2}$

${ }^{1}$ Bone Densitometry and ${ }^{2}$ Endocrinology, Queen Elizabeth Hospital Birmingham, and University of Birmingham, Edgbaston, Birmingham B15 2TH, UK.

\section{Correspondence:}

Nicola Crabtree

Bone Densitometry

Queen Elizabeth Hospital

Edgbaston

Birmingham B15 2TH

United Kingdom

Tel: $\quad$ +44(0) 1216272591

FAX: $\quad+44(0) 1216272386$

E-mail: Nicola.Crabtree@uhb.nhs.uk

Key Words: FRAX ${ }^{\circledR}$; NOGG; osteoporosis; fracture

Acknowledgements and affiliations: We would like to thank all the staff of the Bone

Density Unit at Queen Elizabeth Hospital for their help with the study.

Competing interests: The Authors have no competing interests to disclose

Funding: This study was unfunded.

Word Count: Text: 2010, Abstract: 248, Figures: 4, Tables: 2 


\begin{abstract}
:
Objective: To assess whether clinician-determined treatment intervention thresholds are in line with the assessment of fracture risk provided by FRAX $^{\circledR}$ and treatment recommendations provided by UK guidelines produced by the National Osteoporosis Guidelines Group (NOGG).
\end{abstract}

Design, Patients and Measurements: This was a retrospective cohort analysis of 288 patients consecutively referred for DXA scanning from primary care immediately prior to the introduction of the $\mathrm{FRAX}^{\circledR}$ algorithm. In addition to DXA assessment, patients completed a clinical risk factor questionnaire which included risk factors used in the FRAX ${ }^{\circledR}$ algorithm. Initial risk assessment and treatment decisions were performed after DXA. FRAX $^{\circledR}$ was used, retrospectively, with femoral neck T-score, to estimate fracture risk which was applied to NOGG to generate guidance on treatment intervention. Clinician- and NOGG-determined outcomes were audited for concordance.

Results: There was concordance between clinician and NOGG treatment decisions in 210 (72.9\%) subjects. Discordance was observed in 78 (27.1\%) subjects. In the discordant group, 7 subjects were given lifestyle advice when NOGG recommended treatment, 41 given treatment when NOGG recommended lifestyle advice only, and 30 were referred to a metabolic bone clinic for further evaluation. The reasons for treatment differences in subjects recommended treatment by clinician but not NOGG were largely (90.2\%) due to use of lumbar spine BMD.

Conclusions: There is high concordance between clinician-determined and FRAX ${ }^{\circledR}$-NOGG intervention. The absence of spine BMD from FRAX ${ }^{\circledR}$ is the primary source of discrepancy. This study provides some assurance of the validity of the treatment thresholds generated from FRAX ${ }^{\circledR}$-NOGG in 'real-world' usage. 


\section{INTRODUCTION:}

Decisions regarding who should receive treatment for osteoporosis are based on a range of factors. Since the World Health Organisation (WHO) introduced an operational definition of osteoporosis based on dual-energy x-ray absorptiometry (DXA)-determined T-scores, decisions for treatment have relied heavily on this measure ${ }^{12}$. More recently the importance of additional risk factors such as age and prior fractures have been emphasised and this has been incorporated into some clinical guidelines (e.g. National Institute for Health and Clinical Excellence (NICE) Osteoporosis Technology Appraisals ${ }^{1}$ ) or been used in a more subjective way by specialists to rationalise approaches to treatment. The introduction of the FRAX $^{\circledR}$ algorithm ${ }^{7}$ has resulted in a more robust way to estimate fracture risk although this still has some limitations, including the ability to adjust for some aspects of individual patient risk e.g. number of fractures or dose and duration of glucocorticoid treatment. In the UK an advisory group, the National Osteoporosis Guidelines Group (NOGG), have linked the output scores obtained with FRAX ${ }^{\circledR}$ to guidance on who to investigate with DXA and who to treat without the requirement for prior $\mathrm{DXA}^{8}$. The aims of NOGG are to provide assessment thresholds for the use of BMD i.e. the fracture probabilities at which a BMD test might or might not be recommended, and to provide FRAX $^{\circledR}$ based intervention thresholds, based on the existing UK case-finding strategy. The aim of this retrospective study was to assess whether clinician-determined treatment intervention thresholds (not using FRAX ${ }^{\circledR}$-NOGG) were in line with the objective assessment of fracture risk provided by $\mathrm{FRAX}^{\circledR}$ and treatment intervention thresholds provided by UK guidelines produced by the NOGG.

\section{METHODS:}

The study took place between April 2008 and September 2008 and 288 patients consecutively referred for DXA scanning from a primary care setting were included. The demographic details for these patients are shown in table 1. An outline schema of the patient assessment is shown in figure 1. Standard DXA assessment was performed at the hip and spine using a Lunar Prodigy scanner. Patients also completed a clinical risk factor questionnaire that has been in routine use within the unit for several years and included pertinent risk factors used to populate the FRAX $^{\circledR}$ algorithm. This self completed questionnaire asked for details of previous fractures, height loss, parental history of fracture, glucocorticoid use, age at menopause, HRT use and tobacco consumption. Initial risk 
assessment and treatment decisions were performed shortly after the time of DXA scan taking into account the DXA results, information provided by the patient questionnaire and information provided on the patient referral letter e.g. previous medical history, current and previous medication use. Clinical decisions were made by a consultant physician, 3 of whom were involved with the study. The basis for the clinical decisions made by the consultants was not studied systematically here (except where clinical decisions and those indicated by FRAX $^{\circledR}$-NOGG differed) but it would be anticipated that these decisions would be strongly influenced by the UK guidelines available at the time of the study which included the Royal College of Physicians UK guidance from 1999 and those from NICE ${ }^{1,10,11}$.

Initially the FRAX ${ }^{\circledR}$-NOGG guidelines were used to determine whether referral for DXA was warranted initially on the basis of clinical risk factors alone. The FRAX ${ }^{\circledR}$ tool was then used, retrospectively, in conjunction with femoral neck bone mineral density (BMD) Tscore, to estimate fracture risk which was subsequently applied to NOGG to generate guidance on treatment intervention. Clinician- and NOGG-determined outcomes were audited for concordance.

\section{RESULTS:}

\section{Concordance for recommendations for DXA:}

The concordance of recommendations for DXA measurement by FRAX ${ }^{\circledR}$ in those patients actually referred for DXA scanning is shown in figure $2 \mathrm{~A}$. In only $53 \%$ of patients actually referred did FRAX ${ }^{\circledR}$-NOGG guidance suggest referral for DXA. In $5 \%$ of patients NOGG guidance would have suggested treatment without the need for DXA. In $41 \%$ of patients NOGG guidance indicated lifestyle advice alone. The reasons for referral where NOGG guidance would have indicated lifestyle advice alone are shown in figure $2 \mathrm{~B}$. The majority of these patients were referred with an accepted risk factor for osteoporosis that is not incorporated into the FRAX algorithm (osteopaenia on radiograph $\mathbf{n = 3 6}$ family history of non-hip fracture(s) $\mathbf{n}=\mathbf{3 6}$ height loss/kyphosis $\mathrm{n}=11)$. A small number of patients $(\mathrm{n}=12)$ were referred for decisions relating to the continuing use of HRT that had been started due to early menopause. In the remaining 24 patients (7\% of total population) one or more risk factors included in FRAX ${ }^{\circledR}$ were present.

\section{Concordance for recommendations for treatment with DXA results available:}


The concordance of recommendations for treatment based on clinician evaluation of all available information and recommendations based on the $\mathrm{FRAX}^{\circledR}$-NOGG guidance are shown in figure 3A. There was concordance between clinician and NOGG on treatment decision in $210(72.9 \%)$ subjects. A breakdown of the concordant treatment decisions is given in figure 3B. Discordance was observed in $78(27.1 \%)$ subjects. In the discordant group, 7 subjects were given lifestyle advice when NOGG recommended treatment, 41 were given treatment when NOGG recommended lifestyle advice only, and 30 were referred to a metabolic bone clinic for further evaluation. The reasons for treatment differences are shown in figure 4 and table 2. The primary reason for lifestyle advice when NOGG recommended treatment was the absence of osteoporosis determined by DXA (table 2A). The reason for recommendation of active treatment by clinician but not FRAX $^{\circledR}$-NOGG guidance was primarily (37/42 patients) due to the presence of spinal osteoporosis. In the remaining 5/42 patients the contributing factors that suggested treatment are outlined in table $2 \mathrm{~B}$. The reasons for discordant decisions made after patients were seen in the metabolic bone clinic are shown in table $2 \mathrm{C}$. These were all treatment recommendations by physician when NOGG suggested lifestyle and comprised of patients who had either isolated osteoporosis at the spine or had low bone density in the presence of vertebral fractures (some only identified on further investigation).

\section{Concordance of decisions made using FRAX ${ }^{\circledR}$-NOGG without BMD and ultimate clinical decisions with BMD available:}

119 of the individuals referred for DXA in this study would have been recommended lifestyle advice alone using FRAX ${ }^{\circledR}$-NOGG guidance (figure 2A). Of these 119 individuals 103 were ultimately recommended lifestyle advice alone and 16 were recommended treatment. 15 individuals would have been recommended treatment without using FRAX $^{\circledR}$-NOGG. Of these 15 individuals 11 were ultimately recommended for treatment. 


\section{DISCUSSION:}

We retrospectively examined the concordance of decisions actually made by experienced osteoporosis physicians without the use of FRAX ${ }^{\circledR}$ and/or NOGG guidelines and decisions that would have been made if $\mathrm{FRAX}^{\circledR}$-NOGG recommendations had been used in isolation. We found that the majority of patients referred for bone densitometry would have been referred for densitometry using FRAX $^{\circledR}$-NOGG guidelines. The main reason for referral when FRAX $^{\circledR}$-NOGG guidance suggested no treatment/referral was the presence of indications for DXA assessment based on previous guidelines (primarily the Royal College of Physicians guidelines ${ }^{10,11}$ ). Indications such as osteopaenia on radiographs and a family history of low trauma fractures appear valid indications for densitometry even though they were not able to be incorporated into FRAX ${ }^{\circledR}$-NOGG. There was also a high rate of concordance between treatment decisions made by clinicians without the use of FRAX ${ }^{\circledR}$ NOGG and decisions that would have been made if based solely on FRAX ${ }^{\circledR}$-NOGG. The commonest reason by far for discordance in decisions was where active treatment was recommended by a clinician on the basis of low bone density at the spine, information which is not incorporated into the FRAX ${ }^{\circledR}$-NOGG.

A likely reason for the high degree of concordance between experienced clinicians' judgements from UK based specialists and FRAX ${ }^{\circledR}$-NOGG is that the intervention thresholds for NOGG were determined to try to maintain approximate equivalence with previous UK guidelines. This study suggests that this attempt to establish equivalence has been a success. This probably explains why the physicians appeared to incorporate some clinical risk factors (particularly previous fracture, something emphasised by both Royal College and NICE guidance) in their recommendations in contrast to the findings from a recent Canadian study $^{2}$. However, these previous guidelines did not place a central emphasis on hip BMD in contrast to the output of $\mathrm{FRAX}^{\circledR}$-NOGG and this appeared to be the main reason for discordance (both where recommendations were based on patient information/DXA alone and after attendance at the metabolic bone clinic). An important issue that arises from this study is what to do in the setting of discordant BMD at hip and spine where spine BMD is substantially lower than that of the hip. A proportion of patients in the pivotal randomised trials on which most of the data relating to treatments have been derived had this pattern of bone loss and patients appeared to have a beneficial effect of treatment ${ }^{6,9}$. Many health economic models place much less emphasis on the consequences of vertebral fractures 
(especially morphometric fractures) due to their lower direct cost. However, it is now clear that vertebral fractures are themselves associated with increased mortality ${ }^{3-5}$. In clinical practice it would thus appear impossible to totally discount information regarding such a high, treatable, fracture risk, so many of these patients are likely to continue to be treated.

The other situations where there was discordance in recommendations were also interesting. Recommendations for lifestyle advice alone by physician when NOGG indicated treatment appeared to be explained entirely by the absence of osteoporosis on DXA scanning despite the presence of a high fracture risk. The recommendations for lifestyle advice are probably explained by the emphasis on a DXA based diagnosis of osteoporosis intrinsic in previous WHO guidelines and more lately RCP and NICE guidelines. There is also the additional issue of whether bisphosphonates are effective at reducing fracture risk in individuals who have normal BMD. This is an important area of current debate. Our data do however suggest that the overall number of patients where this issue arises is relatively small.

There are a number of limitations to our study. This approach was unable to determine the full potential impact of FRAX ${ }^{\circledR}$-NOGG on referrals for densitometry. We are only able to evaluate patients who have been referred who might not have been, based on FRAX ${ }^{\circledR}$ NOGG. We are clearly unable to assess the population of patients who should have been referred for DXA on the basis of FRAX ${ }^{\circledR}$-NOGG but were not, or the population that were given treatment without recourse for DXA who may or may not have been recommended for treatment on FRAX ${ }^{\circledR}$-NOGG. In this particular health setting, where utilisation of DXA and anti-osteoporosis medications is relatively low, it is likely that there are many patients being seen in primary care who would be recommended for treatment/evaluation by FRAX ${ }^{\circledR}$ NOGG. There was also an inflexible approach used to the FRAX ${ }^{\circledR}-N^{-}$GG guidance. It is stated explicitly in this guidance that there are many situations where fracture risk will be underestimated e.g. patients with clinical vertebral fractures or multiple fractures. A more flexible interpretation of these guidelines, as would be likely in clinical practice, would almost certainly have reduced further some of the discordance between decisions. It should also be noted that the NOGG guidelines suggest that postmenopausal women with a prior fragility fracture can be treated without FRAX assessment although BMD assessment may be appropriate. We decided not to apply this criteria in our study as use of the FRAX ${ }^{\circledR}$-NOGG algorithm does not always lead to a decision to treat in these patients and there would have been ambiguity regarding when BMD assessment would 
be appropriate. If we had taken this more literal interpretation of the NOGG guidance then 3 of the 12 treatment discordant patients in tables $2 B$ and $2 B$ would have been reclassified as concordant.

This study illustrates that the concordance between decisions that were made by a group of UK physicians before the introduction of the FRAX ${ }^{\circledR}$ algorithm and UK based NOGG guidance and those that would have been made using this guidance was high. It also highlights the reasons for discordant advice which were primarily the additional use of bone density results for the spine (leading to more treatment than recommended by NOGG) and the withholding of treatment by physicians in patients with high fracture risk but lacking osteoporosis by densitometric criteria. 
1. National Institute for Health and Clinical Excellence, Technology Appraisal 87. Bisphosphonates (alendronate, etidronate, risedronate), selective estrogen receptor modulators (raloxifene) and parathyroid hormone (teriparatide) for secondary prevention of osteoporotic fragility fractures in post menopausal women. (2005) NICE, London, UK

2. Cranney,A., Tsang,J.F., \& Leslie,W.D. (2009) Factors predicting osteoporosis treatment initiation in a regionally based cohort. Osteoporosis International, 20, 16211625.

3. Ioannidis,G., Papaioannou,A., Hopman,W.M., khtar-Danesh,N., Anastassiades,T., Pickard,L., Kennedy,C.C., Prior,J.C., Olszynski,W.P., Davison,K.S., Goltzman,D., Thabane,L., Gafni,A., Papadimitropoulos,E.A., Brown,J.P., Josse,R.G., Hanley,D.A., \& Adachi,J.D. (2009) Relation between fractures and mortality: results from the Canadian Multicentre Osteoporosis Study. Canadian Medical Association Journal, 181, 265-271.

4. Ismail,A.A., O'Neill,T.W., Cooper,C., Finn,J.D., Bhalla,A.K., Cannata,J.B., Delmas,P., Falch,J.A., Felsch,B., Hoszowski,K., Johnell,O., az-Lopez,J.B., Lopez,V.A., Marchand,F., Raspe,H., Reid,D.M., Todd,C., Weber,K., Woolf,A., Reeve,J., \& Silman,A.J. (1998) Mortality associated with vertebral deformity in men and women: results from the European Prospective Osteoporosis Study (EPOS). Osteoporosis International, 8, 291-297.

5. Kado,D.M., Browner,W.S., Palermo,L., Nevitt,M.C., Genant,H.K., \& Cummings,S.R. (1999) Vertebral fractures and mortality in older women: a prospective study. Study of Osteoporotic Fractures Research Group. Archives of Internal Medicine, 159, 12151220.

6. Kanis,J.A., Johnell,O., Black,D.M., Downs,R.W., Jr., Sarkar,S., Fuerst,T., Secrest,R.J., \& Pavo,I. (2003) Effect of raloxifene on the risk of new vertebral fracture in postmenopausal women with osteopenia or osteoporosis: a reanalysis of the Multiple Outcomes of Raloxifene Evaluation trial. Bone, 33, 293-300.

7. Kanis,J.A., Johnell,O., Oden,A., Johansson,H., \& McCloskey,E. (2008) FRAX and the assessment of fracture probability in men and women from the UK. Osteoporosis International, 19, 385-397.

8. Kanis,J.A., McCloskey,E.V., Johansson,H., Strom,O., Borgstrom,F., \& Oden,A. (2008) Case finding for the management of osteoporosis with FRAX--assessment and intervention thresholds for the UK. Osteoporosis International, 19, 1395-1408.

9. Quandt,S.A., Thompson,D.E., Schneider,D.L., Nevitt,M.C., \& Black,D.M. (2005) Effect of alendronate on vertebral fracture risk in women with bone mineral density $\mathrm{T}$ scores of-1.6 to -2.5 at the femoral neck: the Fracture Intervention Trial. Mayo Clin.Proc., 80, 343-349. 
10. Royal College of Physicians and Bone and Tooth Society of Great Britain. Osteoporosis-clinical guidelines for prevention and treatment. (1999) Royal College of Physicians, London

11. Royal College of Physicians and Bone and Tooth Society of Great Britain. Update on pharmacological interventions and an algorithm for management. (2000) Royal College of Physicians, London

12. World Health Organisation (WHO Study Group) (1994) Assessment of fracture risk and its application to screening for postmenopausal osteoporosis. World Health Organisation Technical Reports Service, 843, 1-129. 
Table 1: Demographic details of the patients included in this study (mean \pm SD or $\%$ of cohort of 288 subjects: FN; femoral neck: RA; rheumatoid arthritis):

\begin{tabular}{|l|l|}
\hline Female (\%) & 88.5 \\
\hline Age (years) & $63+11$ \\
\hline BMI $\left(\mathrm{kg} / \mathrm{m}^{2}\right)$ & $27 \pm 5$ \\
\hline Previous \# (\%) & 37 \\
\hline FN T score & $-1.2 \pm 1.1$ \\
\hline Steroid ever (\%) & 13 \\
\hline RA history (\%) & 2 \\
\hline
\end{tabular}


Table 2: Details of patients discordant for treatment decisions (see figure 4):

A. Decision life-style advice when FRAX ${ }^{\circledR}$-NOGG guidance suggested treat

\begin{tabular}{|c|c|c|c|c|}
\hline $\begin{array}{c}\text { Gender } \\
(\mathrm{F}=\text { female })\end{array}$ & $\begin{array}{c}\text { Age } \\
\text { (Years })\end{array}$ & $\begin{array}{c}\text { Hip BMD } \\
\text { T-score }\end{array}$ & $\begin{array}{c}\text { Spine BMD } \\
\text { T-score }\end{array}$ & $\begin{array}{c}\text { Additional information } \\
\text { (FN T: femoral neck T score) }\end{array}$ \\
\hline F & 55 & -0.9 & -1.2 & FH hip \#, alcohol use, FN T -1.4 \\
\hline F & 62 & 0.8 & 2.8 & Prior \#, FH hip \#, FN T 0.0 \\
\hline F & 52 & -1.3 & -0.4 & Prior \#, alcohol use, prior steroids \\
\hline F & 61 & -1.6 & -2.1 & Prior \#, FH hip \# \\
\hline F & 64 & 0.4 & -0.5 & Prior \#, FH hip \#, FN T -0.3 \\
\hline F & 50 & -2.0 & -1.6 & Prior \#, alcohol use \\
\hline F & 51 & -1.4 & -1.9 & Prior \#, alcohol use \\
\hline
\end{tabular}

B. Physician decision treat when FRAX ${ }^{\circledR}$-NOGG guidance suggested lifestyle advice (for 37 additional patients treatment given on basis of spine osteoporosis)

\begin{tabular}{|c|c|c|c|c|}
\hline $\begin{array}{c}\text { Gender } \\
(\mathrm{F}=\text { female })\end{array}$ & $\begin{array}{c}\text { Age } \\
\text { (Years })\end{array}$ & $\begin{array}{c}\text { Hip BMD } \\
\text { T-score }\end{array}$ & $\begin{array}{c}\text { Spine BMD } \\
\text { T-score }\end{array}$ & Additional information \\
\hline F & 72 & -0.5 & -1.8 & 4 years treatment with alendronate \\
\hline F & 81 & -2.1 & -2.0 & Difficult spine study ?osteoporosis \\
\hline F & 59 & -2.8 & -1.5 & Family history of non-hip \#s \\
\hline F & 69 & 0.2 & -1.1 & Clinical vert \#, freq steroids courses \\
\hline M & 82 & -2.2 & -0.3 & \# hip, kyphosis \\
\hline
\end{tabular}

C. Discordant treatment decisions in metabolic bone clinic (all physician recommendations for treatment when $\mathrm{FRAX}^{\circledR}$-NOGG guidance suggested lifestyle)

\begin{tabular}{|c|c|c|c|c|}
\hline $\begin{array}{c}\text { Gender } \\
(\mathrm{F}=\text { female })\end{array}$ & $\begin{array}{c}\text { Age } \\
\text { (Years) }\end{array}$ & $\begin{array}{l}\text { Hip BMD } \\
\text { T-score }\end{array}$ & $\begin{array}{c}\text { Spine BMD } \\
\text { T-score }\end{array}$ & Fractures present? \\
\hline $\bar{F}$ & 77 & -1.8 & -4.6 & No \\
\hline $\mathrm{F}$ & 50 & -2.1 & -3.0 & No \\
\hline $\mathrm{F}$ & 70 & -0.7 & -1.7 & Yes, 2 clinical vertebral \\
\hline $\mathrm{F}$ & 76 & -2.2 & -1.7 & Yes, multiple morphometric vertebral \\
\hline $\mathrm{F}$ & 56 & -0.7 & -1.5 & Yes, 1 morphometric vertebral \\
\hline $\mathrm{F}$ & 76 & -2.8 & -4.5 & No \\
\hline $\mathrm{F}$ & 50 & -1.7 & -2.8 & No \\
\hline
\end{tabular}




\section{LEGEND TO FIGURES:}

Figure 1: Schema illustrating the structure of the audit:

There were 2 questions audited in this study. Firstly, the concordance of actual referral indications for our unit and those of $\mathrm{FRAX}^{\circledR}$-NOGG for 288 patients involved in this study. Secondly, the concordance of clinician determined treatment recommendations with guidelines by $\mathrm{FRAX}^{\circledR}$-NOGG. CRFs, clinical risk factors.

Figure 2: Application of FRAX ${ }^{\circledR}-N O G G$ guidance without the availability of DXA information in patients actually referred for DXA:

A. Number of patients condordant/discondordant for FRAX ${ }^{\circledR}-$ NOGG recommendations. B. Breakdown of reasons for disconcondance where referral was made by a clinician but would not have been based on FRAX ${ }^{\circledR}$-NOGG. Treated menopause refers to individuals treated with HRT for an early menopause where decisions regarding continuing use were needed.

Figure 3: Concordance of intervention decisions made by experienced clinician and those recommended by FRAX ${ }^{\circledR}$-NOGG guidance with DXA information available:

Concordance for decisions is shown in A. B. Breakdown of recommendations for treatment in patients where there was concordance for treatment.

Figure 4: Reasons for discordant recommendations by experienced clinician and FRAX ${ }^{\circledR}$ NOGG guidance 


\section{Figure 1:}

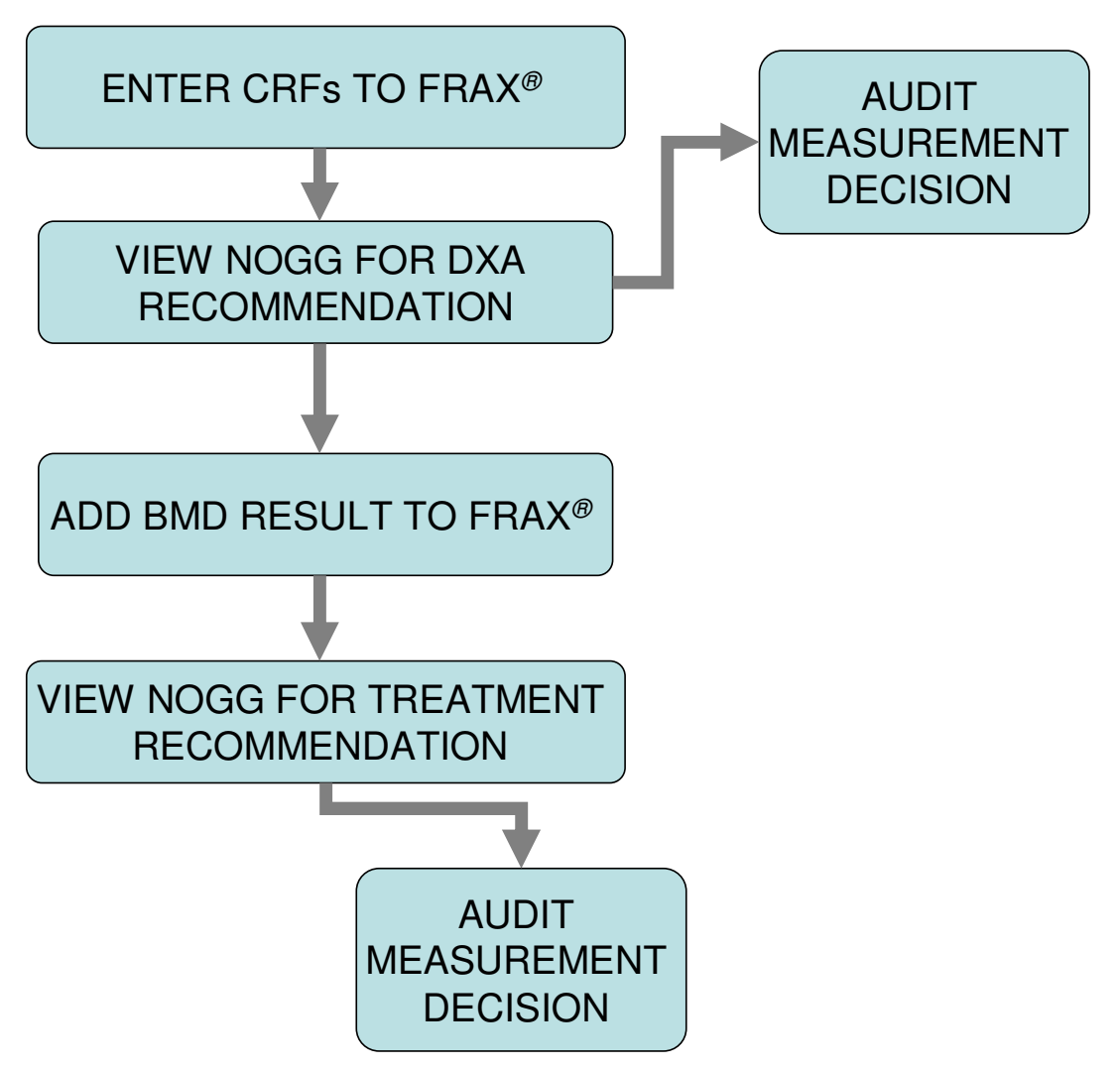




\section{Figure 2:}

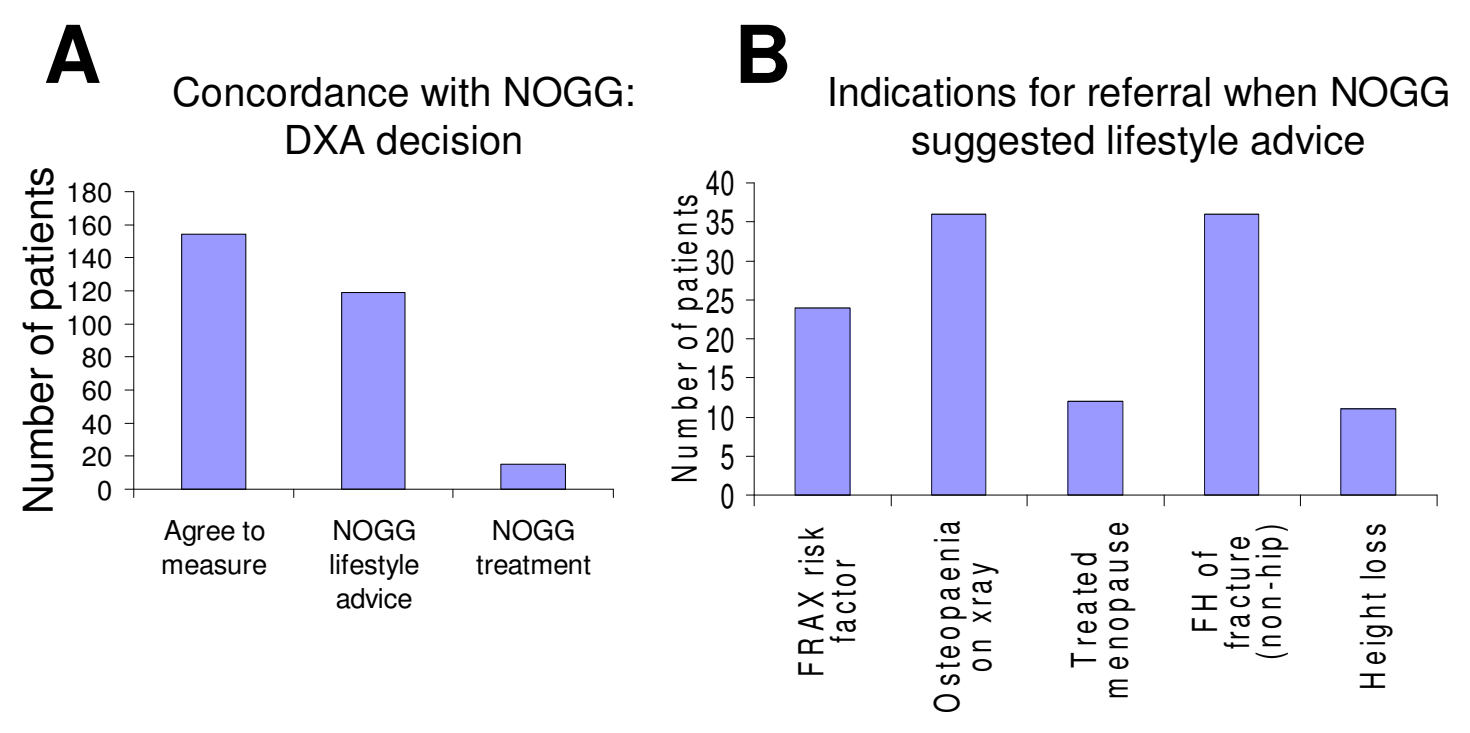

2 
Figure 3:

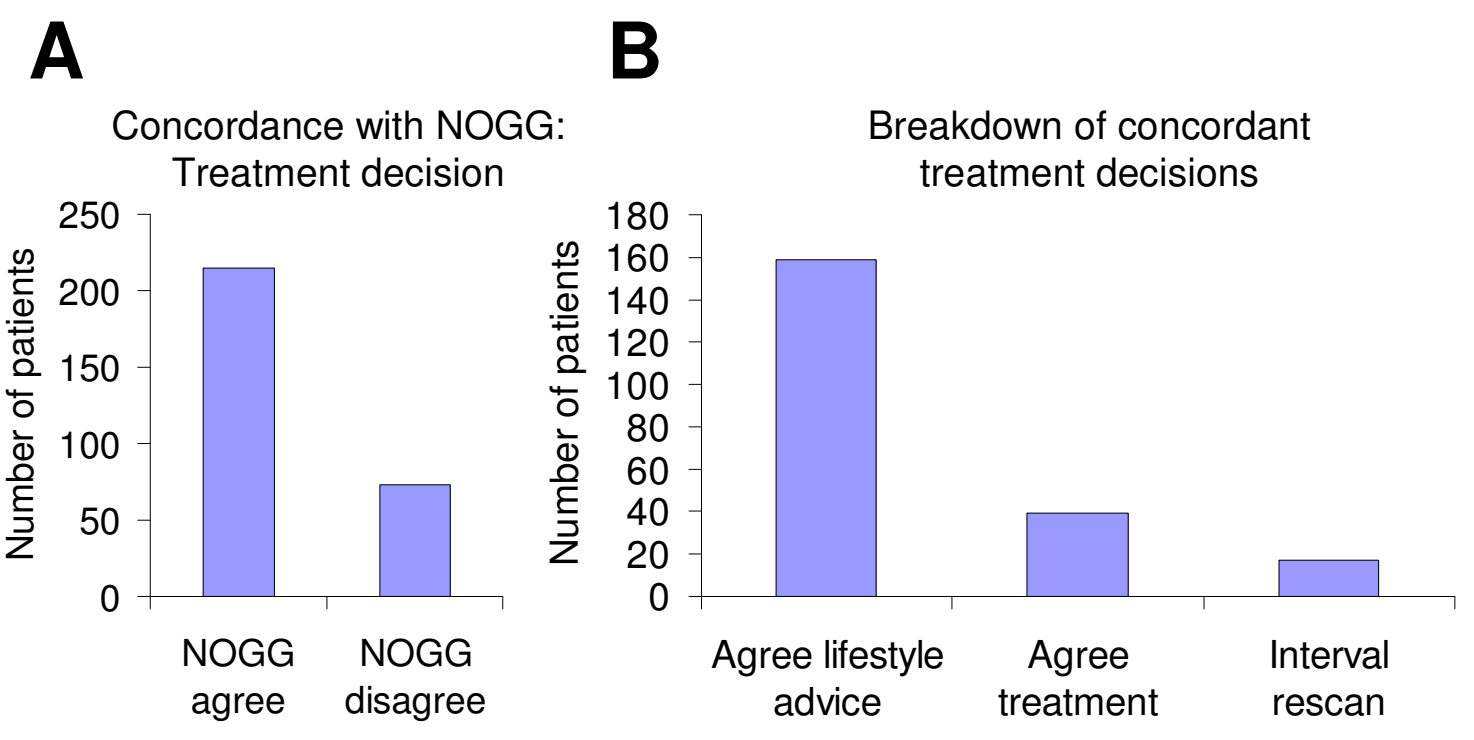




\section{Figure 4:}

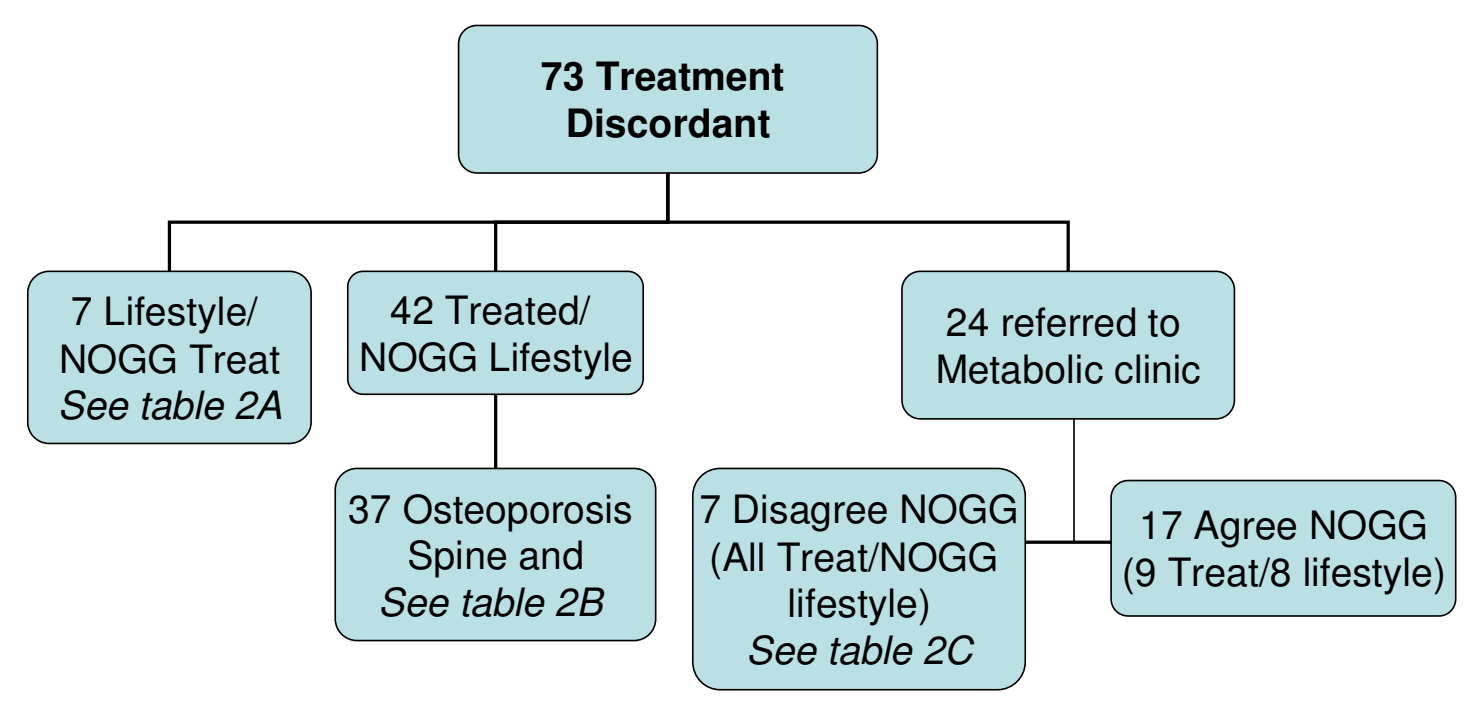

